\title{
SOBREVIVÊNCIA E CRESCIMENTO INICIAL DE ESPÉCIES ARBÓREAS EM ÁREAS DE PASTAGENS DEGRADADAS NO SUL DE MINAS GERAIS
}

\author{
Bárbara Regina Mendonça ${ }^{1},{\text { Fernanda de } \text { Carvalho }^{2} \text {, Renato Luiz Grisi Macedo }}^{3}$, \\ Nelson Venturin ${ }^{4}$, Regis Pereira Venturin ${ }^{5}$
}

${ }^{1}$ Engenheira Florestal, Mestre em Engenharia Florestal pelo programa de pósgraduação da Universidade Federal de Lavras-UFLA, Lavras, Minas Gerais.

${ }^{2}$ Engenheira Florestal, Doutoranda em Engenharia Florestal pelo programa de pósgraduação da Universidade Federal de Lavras-UFLA, Lavras, Minas Gerais

(fernandacarva@hotmail.com).

${ }^{3}$ Professor Titular do Departamento de Ciências Florestais da Universidade Federal de Lavras-UFLA, Lavras, Minas Gerais.

${ }^{4}$ Professor Sênior do Departamento de Ciências Florestais da Universidade Federal de Lavras-UFLA, Lavras, Minas Gerais.

${ }^{5}$ Pesquisador da EPAMIG-Lavras, Minas Gerais

Recebido em: 08/04/2017 - Aprovado em: 10/06/2017 - Publicado em: 20/06/2017 DOI: 10.18677/EnciBio_2017A95

Este estudo teve como objetivo avaliar o potencial de estabelecimento de oito espécies arbóreas implantadas em pastagens degradadas no sul de Minas Gerais. O experimento foi implantado na Fazenda Experimental da EPAMIG-Unidade de Lavras/MG. O delineamento experimental foi de blocos ao acaso, composto por oito tratamentos (espécies florestais) com quatro repetições (parcelas). As espécies florestais avaliadas foram: mogno africano, cedro australiano (clonal e seminal), eucalipto, teca, guanandi, baru e acácia. As parcelas experimentais foram compostas por quatro linhas de plantio, dispostas no arranjo estrutural $(3 \times(3 \times 2)+$ (7x2))m, constituídas por 48 plantas úteis de um total de 56. As espécies foram avaliadas quanto a porcentagem de sobrevivências aos cinco, 12 e 18 meses após o plantio. Aos 18 meses foram avaliados o diâmetro à altura do peito e altura, e aos 12 e 18 meses foram avaliados a área de cobertura da copa. As espécies florestais avaliadas apresentaram diferentes potenciais de estabelecimento, sendo o eucalipto, a acácia, teca, mogno e o baru a apresentar os maiores índices de sobrevivência. $O$ eucalipto juntamente com a acácia apresentou maior crescimento em altura e diâmetro, além de maior área de cobertura de copa mostrando-se eficientes no estabelecimento inicial em pastagens degradadas, apresentando potencial de utilização em sistemas silvipastoris.

PALAVRAS-CHAVE: integração-lavoura-pecuária-floresta, sistemas agroflorestais, recuperação de áreas degradadas 


\title{
SURVIVAL AND INITIAL GROWTH OF TREE SPECIES INDICATED FOR INTEGRATED LIVESTOCK FORESTRY SYSTEMS IN SOUTH OF MINAS GERAIS
}

\begin{abstract}
The aim of study was to determine the potential for establishment of eight tree species in a integrated livestock forestry systems introduced in degraded pastures. The experiment was established in the southern region of the state of Minas Gerais, in the farm of EPAMIG-Unit Lavras/MG. The experimental design was a randomized block design, consisting of eight treatments (forest species) with four replications. The forest species was Khaya senegalensis, Toona ciliata - clonal and seminal), clone of Eucalyptus 1528 (Eucalyptus grandis clone $x$ urophylla), Tectona grandis, Callophyllum brasiliensis, Dipteryx alata and Acacia mangium. The experimental plots were planted four rows arranged in estrutural arrangement $(3 \times(3 \times 2)+(7 \times 2)) \mathrm{m}$, consisting of 48 plants of each forest species to be studied. Forest species were assessed as the percentage of survival at five, 12 and 18 months after planting, at 18 months were evaluated the diameter at breast height and height, and 12 and 18 months were evaluated Cup coverage. Forest species assessed showed different potential establishment, and Eucalyptus, Acacia mangium, Tectona grandis, Khaya senegalensis and Dipteryx alata to present the highest survival rates. Eucalyptus with Acacia showed higher growth in height and diameter and greater canopy coverage area proved to be effective in the initial establishment in degraded pastures, with potential use in integrated livestock forestry systems.
\end{abstract}

KEYWORDS: integration-crop-livestock-forest, agroforestry, reclamation

\section{INTRODUÇÃO}

A degradação de pastagens causa grandes prejuízos ambientais e econômicos no Brasil. Estima-se atualmente que as pastagens ocupam em torno de 172 milhões de hectares do território nacional, sendo que destes, 40 milhões encontram-se diferentes estágios de degradação (VILELA et al., 2015).

Diante deste contexto, agricultores, técnicos e cientistas vêm desenvolvendo formas de produção que buscam reverter o processo de degradação. Dentre estas formas de produção, os sistemas agroflorestais, dentre esses o silvipastoris, permitem otimizar a produção por unidade de área, seguindo sempre os preceitos de conservação dos recursos naturais, através dos aspectos de dinamismo e interação entre os componentes do sistema (SILVA, 2013).

Os sistemas silvipastoris são uma modalidade de sistema de produção animal e vegetal que envolve a consorciação de espécies arbóreas com pastagens para criação de animais domésticos ou silvestres (SILVA, 2013). A importância desses sistemas está, entre outras, na recomposição do componente florestal na paisagem, com benefícios como a renovação do ciclo de nutrientes (FREITAS et al., 2013), na fixação de carbono atmosférico (ROCHA et al., 2014), melhoria dos atributos químicos, físicos e biológicos do solo (CORDEIRO et al., 2015a) e na promoção de conforto térmico aos animais (ALVES et al., 2015).

Além disso, os sistemas silvipastoris proporcionam melhor aproveitamento da área, melhoria da produtividade, da qualidade dos produtos e aumento da renda das atividades agropecuárias, integrando as explorações de pecuária e/ou floresta em áreas já desmatadas, como alternativa aos monocultivos tradicionais (CORDEIRO et al., 2015b; KLUTHCOUSKI et al., 2015; SALTON et al., 2015). No entanto, a adoção de sistemas silvipastoris tem sido lenta, principalmente pela necessidade de 
um planejamento mais elaborado e investimentos iniciais mais altos (REIS et al., 2015).

Dentro deste cenário, a implantação de sistemas silvipastoris tem sido apontada como uma das opções para a recuperação de pastagens degradadas, sendo indicada para diversas situações onde fosse planejada a recuperação da produtividade da pastagem e diversificação das atividades econômicas, com benefícios ambientais (MACEDO \& ZIMMER, 2015). Entretanto, estudos de técnicas de manejo para o estabelecimento de sistemas silvipastoris verdadeiros, ou seja, aqueles sistemas onde árvores e pastagem conviverão por longos períodos, são pouco conhecidos e validados no Brasil e no mundo, o que dificulta a sua adoção por parte do setor produtivo. Inserido neste contexto, buscou-se neste estudo avaliar a porcentagem de sobrevivência e o estabelecimento inicial de oito espécies florestais visando sua utilização em sistemas silvipastoris diretamente sobre áreas de pastagens degradadas, para simplificar e reduzir etapas na adoção de tais sistemas, visando aumentar a sustentabilidade econômica e ambiental da atividade pecuária baseada em pastagens.

\section{MATERIAL E MÉTODOS}

O experimento foi implantado no ano de 2012 na região Sul do estado de Minas Gerais, na Fazenda Experimental da EPAMIG, Unidade de Lavras, que está localizada a uma latitude $21^{\circ} 14^{\prime} 43^{\prime \prime}$ sul e a uma longitude $44^{\circ} 59^{\prime} 59^{\prime \prime}$ oeste, a altitude é de 919 metros. O clima de Lavras, segundo a classificação climática de Köppen, é Cwa, temperado chuvoso (mesotérmico) com inverno seco e verão chuvoso, subtropical, com inverno seco e temperatura do mês mais quente maior que $22{ }^{\circ} \mathrm{C}\left(22,1^{\circ} \mathrm{C}\right.$ em fevereiro). A precipitação anual é de $1529,7 \mathrm{~mm}$. A área em questão está localizada em áreas de cerrado com pastagens degradadas de braquiária, assentadas principalmente sobre solos Argissolos Vermelhos.

O delineamento experimental foi de blocos ao acaso, composto por oito tratamentos (espécies florestais) com quatro repetições. As espécies florestais utilizadas foram: mogno africano (Khaya senegalensis A. Juss), cedro australiano (Toona ciliata M. Roemer, clonal e seminal), Eucalipto - clone1528 (clone de Eucalyptus grandis x urophylla), teca (Tectona grandis L. F), guanandi (Callophyllum brasiliensis Cambess), baru (Dipteryx alata Vog.) e acácia (Acacia mangium Willd). Ressalta-se que a espécie de cedro australiano confere dois tratamentos, sendo um seminal e o outro clonal.

As espécies florestais foram implantadas nas pastagens em espaçamento duplo, com 3 linhas de plantio em espaçamento 3X2m intercaladas por uma linha simples no espaçamento $7 \times 2 \mathrm{~m}$. As parcelas experimentais foram constituídas por quatro linhas de plantio, totalizando 48 plantas úteis de 56 plantas de cada uma das espécies florestais, sendo representadas na Figura 1. 


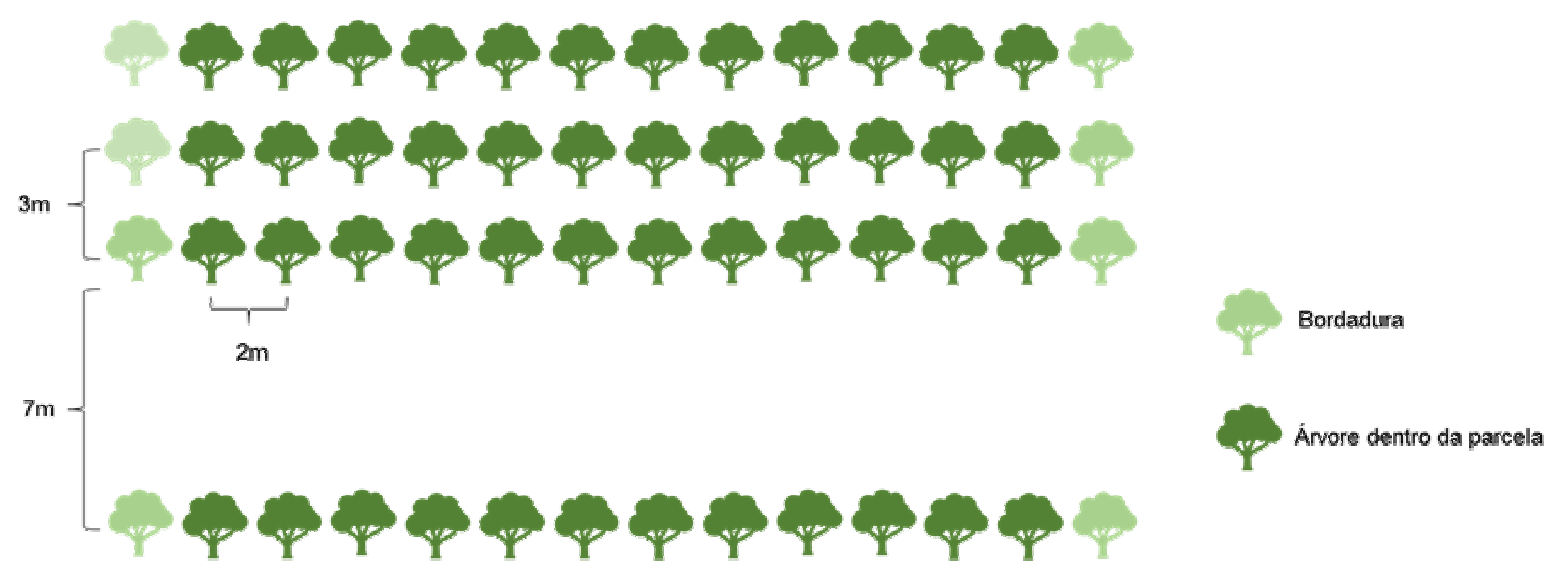

FIGURA 1. Esquema do arranjo estrutural e detalhe da parcela experimental utilizada para cada espécie florestal avaliada neste estudo.

Fonte: autores.

A implantação das espécies florestais foi realizada conforme as exigências daquela de maior necessidade de tratos culturais, sendo esta o cedro, padronizando assim a adubação e demais operações de cultivo, respeitando-se, porém, as exigências de práticas silviculturais e fitossanitárias específicas de cada uma destas. Nas linhas de plantio foi feita uma subsolagem, seguida por adubação de base e plantio das mudas. Nas entre linhas foi feita uma correção de solo no ano de implantação do sistema, visando a recuperação da pastagem. O replantio das mudas florestais foi realizado até 30 dias após o plantio. Aos cinco, 12 e 18 meses após o plantio foi avaliada a porcentagem de sobrevivência das espécies florestais avaliadas neste estudo. Aos 18 meses após o plantio foram avaliados: o diâmetro à altura do peito (DAP), altura total da planta (H), e a área de projeção da copa (APC).

A porcentagem de sobrevivência foi determinada com base na contagem das plantas das espécies florestais vivas, estabelecendo-se uma proporção em relação ao número total das plantas da área útil da parcela. Para altura total das plantas, foram consideradas todas as árvores vivas encontradas nas parcelas úteis, onde com o auxílio de uma régua telescópica mediu-se da base do caule até o ápice da planta. A área de projeção da copa (APC) (expressa em $\mathrm{m}^{2}$ ), foi obtida através das medições da projeção da copa entre as plantas na linha de plantio (PCEP) e entre as linhas de plantio (PCEL) e foi calculada por meio da fórmula:

$$
\mathrm{APC}=(\mathrm{PCEL}) \times(\mathrm{PCEP}) \times 3,144
$$

Os dados obtidos foram submetidos à análise de variância empregando-se o programa de análise estatística SISVAR, versão 5.3 (FERREIRA, 2011). Os efeitos dos tratamentos foram comparados pelo teste de Scott-Knott, a $5 \%$ de probabilidade.

\section{RESULTADOS E DISCUSSÃO}

A porcentagem de sobrevivência variou de acordo com as espécies florestais avaliadas, sendo as espécies: Acacia mangium, Khaya senegalensis, Tectona grandis, Eucalyptus (clone 1528) e Dipteryx alata a apresentar as maiores porcentagens de sobrevivência em relação a Toona ciliata seminal e clonal e o Calophyllum brasiliense em todas as épocas de avaliação (cinco, 12 e 18 meses) (Tabela 1). 
TABELA 1. Porcentagem de sobrevivência de oito espécies florestais implantadas em área de pastagem degradada, localizada em Lavras/MG após cinco, 12 e 18 meses do plantio.

\begin{tabular}{lcccc}
\hline \multirow{2}{*}{ Espécie } & Nome comum & \multicolumn{3}{c}{ Sobrevivência (\%) } \\
\cline { 3 - 5 } & & $\mathbf{5 ~ m e s e s}$ & $\mathbf{1 2}$ meses & $\mathbf{1 8 ~ m e s e s}$ \\
\hline Toona ciliata M. Roemer (semente) & cedro australiano & $63,54 \mathrm{~b}$ & $\mathbf{4 8 , 4 4 \mathrm { b }}$ & $\mathbf{4 8 , 4 4 \mathrm { b }}$ \\
Toona ciliata M. Roemer (clone) & cedro australiano & $\mathbf{4 7 , 9 2 \mathrm { c }}$ & $54,69 \mathrm{~b}$ & $53,13 \mathrm{~b}$ \\
Tectona grandis L. F & teca & $95,31 \mathrm{a}$ & $96,35 \mathrm{a}$ & $96,35 \mathrm{a}$ \\
Khaya senegalensis A. Juss & mogno africano & $97,40 \mathrm{a}$ & $96,88 \mathrm{a}$ & $95,31 \mathrm{a}$ \\
Calophyllum brasiliense Cambess & guanandi & $77,60 \mathrm{a}$ & $58,33 \mathrm{~b}$ & $55,73 \mathrm{~b}$ \\
Acacia mangium Willd & acácia & $98,44 \mathrm{a}$ & $97,40 \mathrm{a}$ & $97,40 \mathrm{a}$ \\
Dipteryx alata Vog. & baru & $91,15 \mathrm{a}$ & $91,67 \mathrm{a}$ & $91,15 \mathrm{a}$ \\
Eucalyptus (clone 1528) & eucalipto & $96,88 \mathrm{a}$ & $91,67 \mathrm{a}$ & $91,67 \mathrm{a}$ \\
CV(\%) & & 6,37 & 7,01 & 6,93 \\
\hline
\end{tabular}

Médias seguidas pelas mesmas letras nas colunas, não diferem pelo teste de Scott-Knott, a $5 \%$ de probabilidade.

A capacidade de adaptação, bem como o vigor das mudas de espécies florestais diante das reais condições edafoclimáticas impostas pelo campo são expressos pela porcentagem de sobrevivência (PS) (MACEDO et al., 2001). Neste estudo, a PS das espécies observada aos 12 meses pós-plantio manteve-se praticamente inalterada até a avaliação realizada aos 18 meses após o plantio no campo, evidenciando uma estabilidade diferenciada entre as espécies florestais em suas capacidades/potencial de estabelecimento em áreas de pastagens degradadas no sul de Minas Gerais. Ressalta-se que em todas as avaliações efetuadas não foram observados ataques de pragas (exceto de formigas cortadeiras, porém controladas de forma eficiente) e de fitodoenças nas espécies florestais pesquisadas, o que denota que as mesmas apresentaram, até então, potencial de estabelecimento frente as condições ecológicas locais.

O diâmetro do coleto $(\varnothing)(\mathrm{cm})$ e altura $(\mathrm{H})(\mathrm{m})$ das espécies florestais avaliadas aos 18 meses após o plantio tiveram comportamentos diferenciados $(p \leq$ 0,05 ). As espécies Eucalyptus (clone 1528) e Acacia mangium apresentaram desenvolvimento em diâmetro e altura superior as demais espécies florestais avaliadas neste estudo (Tabela 2). As espécies florestais a apresentar menor desenvolvimento em altura e diâmetro foram: Calophyllum brasiliense, Dipteryx alata, Khaya senegalensis e Tectona grandis (Tabela 2). O crescimento em diâmetro e altura do clone utilizado de Toona ciliata foi equivalente ao seminal (Tabela 2).

Considerando a área de projeção da copa, as espécies Eucalyptys (clone 1528) e Acacia mangium promoveram maior cobertura do solo em relação as demais espécies avaliadas (Tabela 2). Aos 18 meses pôde-se observar um aumento de $135 \%$ da área de cobertura de copa da Acacia mangium em relação aos 12 meses após o plantio (Tabela 2). Tectona grandis, Khaya senegalensis, Calophyllum ENCICLOPÉDIA BIOSFERA, Centro Científico Conhecer - Goiânia, v.14 n.25; p.1171 
brasiliense e Dipteryx alata foram as espécies a possuir menor área de cobertura de copa aos 18 meses após o plantio (Tabela 2).

TABELA 2. Diâmetro $(\varnothing)$ e altura $(H)$ após 18 meses do plantio e área de projeção da copa aos 12 e 18 meses pós-plantio de oito espécies florestais implantadas em área de pastagem degradada, localizada em Lavras/MG após 18 meses do plantio.

\begin{tabular}{lccccc}
\hline Espécie & Nome comum & $\begin{array}{c}\boldsymbol{\sigma} \\
(\mathbf{c m})\end{array}$ & $\begin{array}{c}\mathbf{H} \\
(\mathbf{m})\end{array}$ & $\begin{array}{c}\text { Área de projeção da } \\
\mathbf{c o p a}\left(\mathbf{m}^{2}\right)\end{array}$ \\
\cline { 3 - 6 } & & $\mathbf{1 8}$ meses & $\mathbf{1 2}$ meses & $\mathbf{1 8}$ meses \\
\hline Toona ciliata M. Roemer (semente) & cedro australiano & $14,13 \mathrm{c}$ & $2,30 \mathrm{~d}$ & $0,314 \mathrm{~d}$ & $0,671 \mathrm{c}$ \\
Toona ciliata M. Roemer (clone) & cedro australiano & $19,20 \mathrm{~b}$ & $3,07 \mathrm{c}$ & $0,687 \mathrm{c}$ & $1,098 \mathrm{c}$ \\
Tectona grandis L. F & teca & $10,02 \mathrm{~d}$ & $1,10 \mathrm{e}$ & $0,282 \mathrm{~d}$ & $0,247 \mathrm{~d}$ \\
Khaya senegalensis A. Juss & mogno africano & $12,25 \mathrm{c}$ & $1,13 \mathrm{e}$ & $0,237 \mathrm{~d}$ & $0,162 \mathrm{~d}$ \\
Calophyllum brasiliense Cambess & guanandi & $6,61 \mathrm{e}$ & $1,00 \mathrm{e}$ & $0,035 \mathrm{e}$ & $0,086 \mathrm{~d}$ \\
Acacia mangium Willd & acácia & $31,40 \mathrm{a}$ & $4,61 \mathrm{~b}$ & $2,877 \mathrm{~b}$ & $6,765 \mathrm{a}$ \\
Dipteryx alata Vog. & baru & $5,51 \mathrm{e}$ & $0,84 \mathrm{e}$ & $0,069 \mathrm{e}$ & $0,259 \mathrm{~d}$ \\
Eucalyptus (clone 1528) & eucalipto & $30,11 \mathrm{a}$ & $6,35 \mathrm{a}$ & $4,911 \mathrm{a}$ & $3,361 \mathrm{~b}$ \\
CV(\%) & & 9,57 & 15,84 & 23,28 & 27,60
\end{tabular}

Médias seguidas pelas mesmas letras nas colunas, não diferem pelo teste de Scott-Knott, a 5\% de probabilidade.

A acácia (Acacia mangium) já foi reportada como sendo uma espécie importante na recuperação de áreas degradadas, principalmente por estabelecer simbioses com bactérias fixadoras de nitrogênio (FRANCO \& FARIA, 1997). SOUZA et al. (2001), avaliando o estabelecimento de várias espécies arbóreas em áreas degradadas, ressaltaram a acácia por apresentar maior crescimento em altura, diâmetro, e maior área de cobertura de copa. Além do seu rápido estabelecimento, a acácia produz grande quantidade de serapilheira (FREITAS et al., 2013). favorecendo a atividade biológica do solo e consequentemente a qualidade do solo.

A espécie Calophyllum brasiliense (guanandi) possui crescimento lento e depende de sombra para se desenvolver, no presente estudo pode-se constatar que esta espécie foi uma das que obtiveram menor crescimento em altura e diâmetro, além de menor área de cobertura de copa, resultados semelhantes aos obtidos por SOUZA et al. (2001) ao avaliarem seu desenvolvimento em áreas degradadas sob solos classificados como Podzólicos no sul de Minas Gerais.

O baru (Dipteryx alata) é uma espécie nativa, possuindo ampla distribuição natural. Apesar das potencialidades do baru em sistemas integrados, inclusive na recuperação de áreas degradadas (CARNEIRO et al., 2014), o presente estudo revelou que para as condições de sítio impostas, seu desenvolvimento foi inferior em relação às demais espécies avaliadas, enfatizando a importância da escolha das espécies a serem utilizadas em relação às condições de sítio ao qual a espécie será submetida. 
A teca (Tectona grandis) tem apresentado potencial de desenvolvimento no cerrado localizado em Minas Gerais, no entanto, alguns fatores podem limitar o crescimento inicial, tais como extenso período com insuficiência e irregularidades de precipitações pluviométricas associadas ao nível alto de compactação do solo (MACEDO et al., 2005). No presente estudo, a teca apresentou baixo potencial de desenvolvimento em relação as demais espécies avaliadas, fato não relacionado a precipitação, nem a compactação do solo, mas em decorrência do padrão das mudas utilizadas no plantio, que possuíam dois pares de folhas definitivas, porém com alturas médias de aproximadamente $10 \mathrm{~cm}$.

O cedro australiano (Toona ciliata) é uma espécie com maiores exigências nutricionais (MORETTI et al., 2011) não sendo encontrados na literatura a utilização desta espécie visando a recuperação de áreas degradadas no Brasil. No entanto, esta espécie vem sendo utilizada em sistemas de integração com a cultura do café, (SOUZA et al., 2010), favorecendo o aumento da matéria orgânica e a diversidade da fauna edáfica (TEIXEIRA et al., 2014). Estes últimos autores avaliando o sombreamento do café com a teca não obtiveram os mesmos resultados evidenciando que a espécie vegetal influencia diretamente na diversidade de espécies da fauna do solo e consequentemente nos processos que nele ocorrem, alterando assim a qualidade do solo.

De acordo com MACEDO et al. (2010) o eucalipto se destaca como uma das espécies florestais com grande potencial de utilização em sistemas silvipastoris, principalmente por ser uma espécie de rápido crescimento em diferentes habitats. Neste estudo o clone de eucalipto 1528 mostrou-se com potencial de desenvolvimento em condições de pastagens degradadas.

\section{CONCLUSÕES}

As espécies florestais estudadas, aos 18 meses após o plantio apresentaram diferentes potenciais de estabelecimento em áreas de pastagens degradadas na região de Lavras, sul do estado de Minas Gerais.

As espécies florestais eucalipto clone 1528, acácia, teca, mogno africano e o baru apresentaram porcentagens de sobrevivência superiores a 91,7\% demonstrando maior potencial de estabelecimento e de adaptação às condições edafoclimáticas da região, em relação ás espécies florestais guanandi e cedro (seminal e clonal), que apresentaram porcentagens de sobrevivência inferiores a $58,3 \%$.

As espécies florestais eucalipto clone 1528 e acácia se destacaram das demais espécies por apresentarem maior crescimento em altura $(\mathrm{H})$ e diâmetro a altura do peito (DAP) e maior área de cobertura de copa, comprovando suas características de rápido crescimento e eficiente estabelecimento inicial em áreas de pastagens degradadas na região de Lavras, sul do estado de Minas Gerais.

\section{AGRADECIMENTOS}

Os autores agradecem ao CNPq, FAPEMIG e CAPES.

\section{REFERÊNCIAS}

ALVES, F. V.; NICODEMO, M. L. F.; PORFÍRIO-da-SILVA, V. Bem-estar animal em sistema de integração-lavoura pecuária-floresta. In: CORDEIRO, L. A. M.; VILELA, L; KLUTHCOUSKI, J.; MARCHÃO, R. L. (Eds.). Integração Lavoura-PecuáriaFloresta: o produtor pergunta, a Embrapa responde. Brasília, DF: Embrapa, 2015. p. 377-393. (Coleção 500 Perguntas, 500 Respostas). 
CARNEIRO, V. A.; GOMES, H. B.; NASSER, M. D.; RESENDE, H. G. O Baru (Dipteryx alata Vog.) como exemplo de incremento de renda e de sustentabilidade de comunidades rurais no cerrado goiano: um relato de experiência via seminários da disciplina "Sistemas Agrários de Produção e Desenvolvimento Sustentável". Revista InterAtividade, v.2, n. 2, p. 43-51, 2014.

CORDEIRO, L. A. M.; BALBINO, L. C.; GALERANI, P. R.; DOMIT, L. A.; SILVA, P. C.; KLUTHCOUSKI, J.; VILELA, L.; MARCHÃO, R. L.; SKORUPA, L. A.; WRUCK, F. J. Transferência de Tecnologias para Adoção da Estratégia de Integração LavouraPecuária-Floresta. In: CORDEIRO, L. A. M.; VILELA, L; KLUTHCOUSKI, J.; MARCHÃO, R. L. (Ed.). Integração Lavoura-Pecuária-Floresta: o produtor pergunta, a Embrapa responde. Brasília, DF: Embrapa, 2015b. p. 377-393. (Coleção 500 Perguntas, 500 Respostas).

CORDEIRO, L. A. M.; VILELA, L.; MARCHÃO, R. L.; KLUTHCOUSKI, J. Integração lavoura-pecuária e integração lavoura-pecuária-floresta: estratégias para intensificação sustentável do uso do solo. Cadernos de Ciência \& Tecnologia. v.32, p.15-35, 2015a.

FERREIRA, D. F. Sisvar: a computer statistical analysis system. Ciência e Agrotecnologia, v. 35, n. 6, p. 1039-1042, 2011.

FRANCO, A. A.; FARIA, S. M. The contribution of N2-fixing tree legumes to land reclamation and sustainability inthe tropics. Soil Biology and Biochemistry. v.29, n.5/6, p.897-903, 1997.

FREITAS, E. C. S.; OLIVEIRA-NETO, S. N.; FONSECA, D. M.; SANTOS, M. V.; LEITE, H. G.; MACHADO, V. D. Deposição de serapilheira e de nutrientes no solo em sistema agrossilvipastoril com eucalipto e acácia. Revista árvore, v. 37, p.409417, 2013.

KLUTHCOUSKI, J.; CORDEIRO, L. A. M.; VILELA, L.; MARCHÃO, R. L.; SALTON, J. C.; MACEDO, M. C. M.; ZIMMER, A. H.; BALBINO, L. C.; PORFÍRIO-DA-SILVA, V.; MÜLLER, M. Conceitos e modalidades da estratégia de Integração LavouraPecuária - Floresta. In: CORDEIRO, L. A. M.; VILELA, L.; KLUTHCOUSKI, J.; MARCHÃO, R. L. (Ed.). Integração Lavoura-Pecuária-Floresta: o produtor pergunta, a Embrapa responde. Brasília, DF: Embrapa, 2015. p. 21-33. (Coleção 500 Perguntas, 500 Respostas).

MACEDO, M. C. M.; ZIMMER, A. H. Potencial para adoção da estratégia de integração lavoura-pecuária e de integração lavoura-pecuária-floresta para recuperação de pastagens degradadas. In: CORDEIRO, L. A. M.; VILELA, L.; KLUTHCOUSKI, J.; MARCHÃO, R. L. (Ed.). Integração Lavoura-PecuáriaFloresta: o produtor pergunta, a Embrapa responde. Brasília, DF: Embrapa, 2015. p. 21-33. (Coleção 500 Perguntas, 500 Respostas).

MACEDO, R. L. G.; GOMES, J.E.; VENTURIN, N.; SALGADO, B.G. Desenvolvimento inicial de Tectona grandis L.f. (teça) em diferentes espaçamentos no município de Paracatu, MG. Cerne. v. 11, n. 1, p. 61-69, 2005.

MACEDO, R. L. G.; VALE, A. B.; VENTURIN, N. Eucalipto em sistemas agroflorestais. Lavras, Editora da Universidade Federal de Lavras, 2010. 331p.

ENCICLOPÉDIA BIOSFERA, Centro Científico Conhecer - Goiânia, v.14 n.25; p.1174 2017 
MACEDO, R. L. G.; VENTURIN, N.; TSUKAMOTO FILHO, A.A. Princípios de agrossilvicultura como subsídio do manejo sustentável. Informe Agropecuário, v. 29, n. 1/2, p. 15-26, 2001.

MORETTI, B. S.; FURTINI NETO, A.E.; PINTO, S.I.C.; FURTINI, I.V.; MAGALHÃES, C.A.S. Crescimento e nutrição mineral de mudas de cedro australiano (Toona ciliata) sob omissão de nutrientes. Cerne. v.17, n.4, p.453-463, 2011.

REIS, J. C.; PEREIRA, M. A.; RICHETTI, A.; AMARO, G. C.; ARCO-VERDE, M. F. Análise econômico financeira da estratégia de integração lavoura-pecuária-floresta. In: CORDEIRO, L. A. M.; VILELA, L; KLUTHCOUSKI, J.; MARCHÃO, R. L. (Eds.). Integração Lavoura-Pecuária-Floresta: o produtor pergunta, a Embrapa responde. Brasília, DF: Embrapa, 2015. p. 377-393. (Coleção 500 Perguntas, 500 Respostas).

ROCHA, G. P.; FERNANDES, L. A.; CABACINHA, C.D.; LOPES, I. D. P.; RIBEIRO, J. M.; FRAZÃO, L. A.; SAMPAIO, R. A. Caracterização e estoques de carbono de sistemas agroflorestais no Cerrado de Minas Gerais. Ciência Rural. v. 44, p.11971203, 2014.

SALTON, J. C.; OLIVEIRA, P.; TOMAZI, M.; RICHETTI, A.; BALBINO, L. C.; FLUMIGNAM, D.; MERCANTE, F.M.; MARCHÃO, R. L.; CONCENÇO, G.; SCORZA JUNIOR, R. P.; ASMUS, G. L. Benefícios da adoção da estratégia de Integração Lavoura-Pecuária-Floresta. In: CORDEIRO, L. A. M.; VILELA, L; KLUTHCOUSKI, J.; MARCHÃO, R. L. (Ed.). Integração Lavoura-Pecuária-Floresta: o produtor pergunta, a Embrapa responde. Brasília, DF: Embrapa, 2015. p. 35-51. (Coleção 500 Perguntas, 500 Respostas).

SILVA, I.C. Sistemas agroflorestais. $1^{\circ}$ edição. Itabuna: SBSAF, 2013.

SOUZA, H.N.; CARDOSO, I.M.; FERNANDES, J.M.; GARCIA, F.C.P.; BONFIM, V.R.; SANTOS, A.C.; CARVALHO, A.F.; MENDONÇA, E.S. Selection of native trees for intercropping with coffee in the Atlantic Rainforest biome. Agroforestry systems. v. 80. p. 1-16, 2010.

SOUZA, P. A.; VENTURIN, N.; MACEDO, R.L.G.; ALVARENGA, M.I.N.; SILVA, V.F. Estabelecimento de espécies arbóreas em recuperação de área degradada pela extração de areia. Cerne. v. 7, n.2, p.043-052, 2001.

TEIXEIRA, A. F. R.; SILVA, V. M.; MENDONÇA, E. de SÁ. Fauna edáfica em sistemas arborizados de café conilon em solo de tabuleiros costeiros. Coffee Science. v. 9, p. 385-393, 2014.

VILELA, P. S; RIBEIRO, T. R.; LÚCIA, M. G. S. D. Estado da arte das pastagens em Minas Gerais. Belo Horizonte. Superintendência Federal de Agricultura de Minas Gerais. 2015. 207 p. 